\title{
Lymphedema distichiasis syndrome may be caused by FOXC2 promoter-enhancer dissociation and disruption of a topological associated domain
}

Mathew Wallis ${ }^{1,2}$, Rachel Pope-Couston ${ }^{1}$, Julia Mansour ${ }^{1}$, David J. Amor ${ }^{3,4}$, Paisu Tang ${ }^{5}$, Sharyn Stock-Myer ${ }^{5}$

1. Tasmanian Clinical Genetics Service, Tasmanian Health Service, C/- The Royal Hobart Hospital, Hobart Tasmania 7001 Australia

2. School of Medicine and Menzies Institute for Medical Research, University of Tasmania, Hobart Tasmania 7001 Australia

3. University of Melbourne Department of Paediatrics,

4. Murdoch Children's Research Institute, Royal Children's Hospital, Flemington Road, Parkville Victoria 3052 Australia

5. Virtus Diagnostics, 344 Victoria Parade, East Melbourne Victoria 3002 Australia

Running title: LDS may be caused by FOXC2 promoter-enhancer dissociation

Funding: Nil

Disclosures: Nil from any author

Corresponding author: Mathew Wallis

Correspondence:

Dr Mathew Wallis

Tasmanian Clinical Genetics Service

C/- The Royal Hobart Hospital

Hobart Tasmania 7001 Australia

Email: mathew.wallis@utas.edu.au

This is the author manuscript accepted for publication and has undergone full peer review but has not been through the copyediting, typesetting, pagination and proofreading process, which may lead to differences between this version and the Version of Record. Please cite this article as doi: 10.1002/ajmg.a.61935

This article is protected by copyright. All rights reserved. 


\begin{abstract}
Lymphedema distichiasis syndrome (LDS) is a rare autosomal dominant condition characterised by lower limb lymphedema, distichiasis, and variable additional features. LDS is usually caused by heterozygous sequence variants in the FOXC2 gene located at $16 q 24$, but in one previous instance LDS has resulted from a balanced reciprocal translocation with a breakpoint at $16 \mathrm{q} 24,120 \mathrm{~kb}$ distal to the $F O X C 2$ gene suggesting a position effect. Here we describe a second family with LDS caused by a translocation involving $16 q 24$. The family were ascertained after detection of a paternally inherited balanced reciprocal translocation $\mathrm{t}(16 ; 22)(\mathrm{q} 24 ; \mathrm{q} 13.1)$ in a pregnancy complicated by severe fetal hydrops. There was a past history of multiple miscarriages in the father's family, and a personal and family history of lymphedema and distichiasis, consistent with the diagnosis of LDS. Using whole genome amplified DNA from single sperm of the male proband, bead array analysis demonstrated that the FOXC2 gene was intact and the chromosome 16 breakpoint mapped to the same region $120 \mathrm{~Kb}$ distal to the $F O X C 2$ gene. This case highlights the clinical consequences that can arise from a translocation of genomic material without dosage imbalance, and that it is increasingly feasible to predict and characterise possible effects with improved access to molecular techniques.
\end{abstract}

Keywords (3-5): FOXC2, lymphedema, topological associated domain, translocation 


\section{Introduction}

Apparently balanced translocations (ABTs) are found in approximately 1 in 500 individuals, are inherited at least $80 \%$ of the time, and affect all chromosomes in a seemingly randomly distributed fashion (Fantes et al., 2008; Jacobs et al., 1992; Warburton, 1991). Carriers of ABTs are seen frequently in clinical genetics services, mainly to discuss their chance of having a child with either a balanced or unbalanced chromosome rearrangement. Less commonly, the ABT itself can be pathogenic, via mechanisms that include alteration of expression patterns in nearby cis regulatory elements, an imbalance at or near the breakpoint region, production of a chimeric gene, or a position effect on a gene distant from the breakpoint (De Gregori et al., 2007; Fantes et al., 2008; Higgins et al., 2008; Thomas et al., 2010).

ABTs are thought to arise from two random double-strand chromosome breaks followed by ligation (non-homologous end joining; NHEJ). They are termed apparently balanced because detailed analysis can reveal cryptic rearrangements in at least one third of cases (Baptista et al., 2008; De Gregori et al., 2007; Schluth-Bolard et al., 2009), the presence of which provides further evidence for NHEJ as the predominant causative mechanism, as does a lack of sequence similarity between the breakpoint regions. The proportion of imbalances at the breakpoint region is more common in patients with an abnormal phenotype; however, patients with a de novo ABT and an abnormal phenotype may still have no obvious detectable chromosome imbalance, suggesting an alternate mechanism of disease in some individuals (Baptista et al., 2008; De Gregori et al., 2007; Fantes et al., 2008).

Most genes require several cis-acting distant genomic elements for spatiotemporally correct expression, and these can be located up to $1 \mathrm{Mb} 5^{\prime}$ or $3^{\prime}$ from the gene (Howard \& Davidson, 2004). These elements can be located within introns of nearby genes and most do not contact the nearest promoter and skip one or more genes (Howard \& Davidson, 2004; Kleinjan \& van Heyningen, 2005). The cis-spreading of a silencing signal (such as Xist) or signals that can move between chromosomes (including proteins and RNAs) can influence long-range regulation, but distal regulatory elements are often brought together into physical proximity through the formation of chromatin loops (Dekker \& Mirny, 2016; Nora et al., 2012) to form self-interacting topologically associating domains (TADs) (Rao et al., 2014; Spielmann, Lupiáñez, \& Mundlos, 2018). Balanced chromosomal abnormalities can alter the copy number of regulatory elements, but they can also disrupt higher-order chromatin organisation such as TADs, influencing the expression of genes distant from the breakpoints and causing disease (Spielmann et al., 2018).

Lymphedema distichiasis syndrome (LDS; OMIM \#153400) is characterised by lower limb lymphedema that occurs from late childhood or puberty, frequently accompanied by 
distichiasis and its complications, including corneal irritation, recurrent conjunctivitis and photophobia. In LDS, distichiasis can range from a full second row of eyelashes, through to a few extra hairs. Other less common features of LDS include non-immune hydrops fetalis, congenital heart disease, cleft palate, and renal anomalies. LDS is variable in presentation both within and between families. LDS is caused by heterozygous pathogenic variants in the FOXC2 gene, located at 16q24 (Fang et al., 2000). In the LDS gene discovery paper, the authors identified truncating heterozygous variants in the FOXC2 gene in two families with LDS and, in a third subject they hypothesised a position effect as the cause of LDS due to an $A B T$ (Fang et al., 2000). In that family, the presence of the ABT helped confirm that the locus for LDS was at 16q24 (Erickson et al., 1995; Fang et al., 2000). This article describes a family with LDS diagnosed after a couple was referred to clinical genetics due to recurrent pregnancy loss related to a familial $A B T, t(16 ; 22)(q 24 ; q 13.1)$, representing the second example of LDS caused by an ABT with breakpoint at $16 q 24$.

\section{Case Report}

The couple presented to the clinical genetics service when pregnant with their third child. The male partner was known to carry a balanced reciprocal translocation $\mathrm{t}(16 ; 22)(\mathrm{q} 24 ; \mathrm{q} 13.1)$ and also reported history of lymphedema. On examination he was found to have accessory eyelashes and lower limb lymphedema consistent with a diagnosis of lymphedema distichiasis syndrome (LDS).

The pedigree is shown in Figure 1. Elsewhere in the family, the male partner's father also carried the balanced translocation and was reported to have lower limb lymphedema and a history of removal of eyelashes due to irritation. The paternal grandfather was also reported to have a history of lymphedema but was deceased and no karyotype had been performed. In addition, there was also a history of multiple miscarriages in the mother of the male partner, as well as a stillbirth at 25 weeks gestation with a reported neck abnormality that may have represented hydrops.

The couple had two previous pregnancies. Their first pregnancy resulted in the birth of a healthy daughter with normal chromosome microarray analysis at prenatal diagnosis. During their second pregnancy, a 12-week ultrasound detected increased nuchal thickness and malformations of the kidneys and brain, and the pregnancy was terminated at 13 weeks of gestation. Chromosome microarray (CMA) on the products of conception showed a normal female molecular karyotype. A G-banded karyotype was not performed for either of these two pregnancies.

In their third pregnancy a 12-week ultrasound showed a severely hydropic fetus with a nuchal translucency of $5.6 \mathrm{~mm}$. Non-invasive prenatal screening and CMA from an amniocentesis sample were normal. A G-banded karyotype on the amniocentesis sample showed the $\mathrm{t}(16 ; 22)(\mathrm{q} 24 ; \mathrm{q} 13.1)$ balanced translocation. Ultrasound at 22 weeks' gestation 
showed increased hydrops causing bilateral pleural effusions and the couple elected to terminate the pregnancy.

\section{Methods}

To determine if FOXC2 was interrupted by this translocation, and in preparation for preimplantation genetic testing (PGT), single sperm from the male translocation carrier were loaded into tubes containing 4uL 1x PBS (Cell Signalling Technology). The sperm samples were then lysed, and the DNA was whole genome amplified (REPLI-g Single Cell Kit, Qiagen). The amplified DNA was analysed using the Human Karyomap-12 bead array (Illumina USA), as per manufacturer's instructions and Bluefuse Multi v4.3 software used to determine the position of the translocation breakpoints. Single sperm that are unbalanced for the translocation have loss and/or gain of the segments involved in the translocation, and therefore the breakpoints of the translocation can clearly be visualised.

\section{Results}

A total of six single sperm were whole genome amplified and analysed on the bead array. Three sperm were balanced for the translocation, showing normal copy number of chromosomes 16 and 22. Three sperm were unbalanced, and two of these unbalanced sperm contained derivative chromosome 22 with a clear $12 \mathrm{Mb}$ deletion on the $\mathrm{q}$ arm of chromosome 22. One sperm had the derivative chromosome 16, and a deletion of the 3.6 $\mathrm{Mb}$ of the $\mathrm{q}$ arm of chromosome 16 . The high-resolution mapping on the bead array revealed that the translocation breakpoint on chromosome 16 is within a $6.5 \mathrm{~Kb}$ region between 116 and $123 \mathrm{~Kb}$ distal to the 3' end of the FOXC2 gene (Figure 2), between GRCh37 Chr16:86,718,757-86,725,305.

\section{Discussion}

This couple had two pregnancies with abnormalities, one with nuchal edema and other abnormalities and the other with severe fetal hydrops. The molecular karyotype in both these pregnancies was normal, indicating no significant imbalance of chromosome material. The male partner carried an ABT $[\mathrm{t}(16 ; 22)(\mathrm{q} 24 ; \mathrm{q} 13.1)]$ and was clinically diagnosed with LDS. The pregnancy with hydrops was confirmed to carry the ABT. It was therefore proposed that the pregnancy with hydrops might have a severe form of LDS due to an ABTrelated disruption of the FOXC2 locus, as hydrops is a known presentation of LDS (Fang et al., 2000; Lai et al., 2018; Sargent et al., 2014). The cause of the anomalies in the second pregnancy may have been due to a similar mechanism, but no sample was available from this pregnancy to test for the presence or absence of the ABT. Whole genome-amplified single sperm analysis for the male proband with bead array analysis demonstrated that the FOXC2 gene did not contain a copy number variant and the breakpoint was approximately $120 \mathrm{~Kb}$ distal to the FOXC2 gene. This indicated that the cause of disease in this family was 
likely due to the fact that FOXC2 had been dissociated from its downstream regulatory elements.

The position of the $16 q 24$ translocation breakpoint in this family maps to within a $6.5 \mathrm{~kb}$ region that is almost entirely nested within the $12 \mathrm{~kb}$ region to which the translocation breakpoint was mapped in the gene discovery paper (Fang et al., 2000). A breakpoint at this position is likely to disrupt the TAD in which FOXC2 resides and dissociate it from the majority of its enhancer elements (see Figure 3). FOXC2 is located near the boundary of a putative TAD and the majority of enhancer elements for FOXC2 appear to be located downstream of the gene and within the same TAD. Although pathogenic sequence variant in FOXC2 has not been excluded in this family, the breakpoint at $16 q 24.3$ is almost identical to that seen in the gene discovery paper, and the translocation tracked with disease in both families. Additionally, this mechanism of disease has been identified in other forkheaddomain genes where pathogenic sequence variants were not found in the relevant gene (Crisponi et al., 2004; Lai et al., 2001).

A proportion of human disease-associated chromosomal deletions may be pathogenic due to the elimination of TAD boundaries (Ibn-Salem et al., 2014), and multiple different types of structural chromosomal changes can disturb TAD structure and give rise to the same phenotype (Lupiáñez et al., 2015). For example, in patients with congenital anomalies, balanced chromosomal abnormalities may disrupt TADs encompassing known syndromic loci in at least 7\% (Redin et al., 2017) of cases.

FOXC2 is a developmental regulator gene from the 'forkhead' (or winged helix) gene family. Several developmental regulator genes with well-established haploinsufficiency phenotypes, including the forkhead/winged helix group of transcription factors, have been documented to give rise to loss-of-function phenotypes through disruption of long-range control (Kleinjan \& van Heyningen, 2005) and there are multiple examples of translocations causing a position effect on pleiotropic developmental regulator genes (Belloni et al., 1996; Flomen et al., 1998; Roessler et al., 1996; 1997; Trembath et al., 2004; Wallis et al., 1999; Wild et al., 1997). TADs are generally up to $1 \mathrm{Mb}$ in size and are associated with convergent CCCTC-binding factor (CTCF) sites that appear to facilitate cohesion binding and chromatin loop extrusion (Dekker \& Mirny, 2016; Rao et al., 2014). The majority of interactions between promoters and enhancers occur within TAD boundaries and certain types of genes (transfer RNA and housekeeping genes) appear to be enriched near TAD boundaries. TAD boundaries appear to be largely conserved across different species and cell types, and TAD rearrangements disrupt the normal topology of protein-coding genes and their enhancers relative to TAD boundaries, resulting in inappropriate interactions and misexpression (Lupiáñez et al., 2015). 
While ABTs can occasionally be pathogenic, most balanced structural chromosome rearrangements do not directly cause disease and are relatively common in the general population. Reciprocal translocations, Robertsonian translocations, pericentric inversions, and paracentric inversions have a collective birth prevalence of approximately 1 in 200 (Jacobs et al., 1992), while the prevalence of de novo balanced rearrangements is approximately 1 in 2000 (Halgren et al., 2018). The rapid uptake of high-resolution molecular karyotyping techniques has led to a vast improvement in our understanding of the mechanisms and burden of chromosomal disease due to copy number variants (CNVs); however, the proportion of disease caused by ABTs without apparent gain or loss of chromosome material is less well understood (Redin et al., 2015; Halgren et al., 2018). In some part, this may be because standard cytogenetics techniques are no longer employed as a first line test and identifying structural chromosome rearrangements using massively parallel sequencing data is difficult and not yet widely available.

The risk of congenital abnormalities or intellectual disability in prenatally ascertained de novo ABTs is at least $10 \%$ (Warburton, 1991), and closer to $30 \%$ when long-term follow-up for neurodevelopmental and/or neuropsychiatric disorders is taken into account (Halgren et al., 2018). It is therefore important to identify those rare ABTs that might themselves cause a risk of disease and this case demonstrates the importance of taking a full family history when counselling during pregnancy and the importance of thinking broadly about the possibility that an ABT may be associated with another condition in the family. However, the potential clinical consequences arising from a translocation of genomic material without dosage imbalance may be important to consider for all ABT carriers, irrespective of family history or examination findings. With improved access to molecular techniques and a better understanding of spatial gene expression control, it is increasingly feasible to predict and characterise the possible effects of ABTs. Halgren et al. recommended mapping the breakpoints as a first-tier diagnostic test in pregnancies with a de novo $A B T$, and using blinded interpretation of mate-pair sequencing data, showed that this was able to accurately predict a benign outcome for healthy carriers while also predicting an untoward outcome, due to expected disruption of known disease-associated genes or regulatory domains, in almost half of the affected carriers (Halgren et al., 2018).

Haploinsufficiency is the main suspected mechanism of disease in most cases of LDS and while the lymphedema associated with LDS is typically puberty-onset, it can present as hydrops fetalis in its most severe form (Fang et al., 2000; Lai et al., 2018; Sargent et al., 2014). Truncating heterozygous pathogenic variants in FOXC2 have been reported in other families with LDS ascertained due to hydrops fetalis (Fang et al., 2000), but the factors underlying severity and variability in LDS are not well understood and there are no apparent genotype-phenotype correlations (Bell et al., 2001; Berry et al., 2005; Brice, 2002; Erickson, 2001; Erickson et al., 2001; Sholto-Douglas-Vernon et al., 2005; Tavian et al., 2016). The report of phenotype-discordant MZ twins with LDS and truncating FOXC2 variant suggests 
that phenotype disparity in LDS is not necessarily due to other modifying genomic loci (Kumar et al., 2007). It remains possible that the specific translocation in our family is associated with an increased risk of hydrops compared to other FOXC2 variants; however, several members of our family had a classic LDS picture without hydrops, suggesting that the penetrance of hydrops in this family is not significantly different to other families with LDS (Tavian et al., 2020).

\section{Conclusion}

The advice given to couples regarding ABTs often focuses on the fact that chromosomal rearrangements are common and when balanced they are usually benign. Pathogenic ABTs are rare and genetic counselling should largely be reassuring about the clinical impact on carriers for balanced forms. However, it should not be assumed, and health professionals should keep an open mind when evaluating phenotypes that cannot be explained by an unbalanced form of the ABT. After small dosage imbalances have been excluded, fine mapping of the ABT breakpoint region is important to consider as it can help identify nearby genes of interest, especially pleiotropic developmental regulators known to be associated with disease, and may give insight into the possible effects on local TAD structure and gene expression. While likely to be rare, the proportion of human disease due to balanced translocations remains largely unknown. The incidence of de novo translocations in simplex cases should, however, be better understood as analyses for complex cytogenetic rearrangements becomes common practice for patients undergoing clinical diagnostic genomic testing. Similarly, our ability to ascribe pathogenesis will progress as our understanding of spatial gene expression control continues to improve.

\section{REFERENCES}

Baptista, J., Mercer, C., Prigmore, E., Gribble, S. M., Carter, N. P., Maloney, V., et al. (2008). Breakpoint mapping and array CGH in translocations: comparison of a phenotypically normal and an abnormal cohort. American Journal of Human Genetics, 82(4), 927-936. http://doi.org/10.1016/j.ajhg.2008.02.012

Bell, R., Brice, G., Child, A. H., Murday, V. A., Mansour, S., Sandy, C. J., et al. (2001). Analysis of lymphoedema-distichiasis families for FOXC2 mutations reveals small insertions and deletions throughout the gene. Human Genetics, 108(6), 546-551. http://doi.org/10.1007/s004390100528

Belloni, E., Muenke, M., Roessler, E., Traverse, G., Siegel-Bartelt, J., Frumkin, A., et al. (1996). Identification of Sonic hedgehog as a candidate gene responsible for holoprosencephaly. Nature Genetics, 14(3), 353-356. http://doi.org/10.1038/ng1196353

Berry, F. B., Tamimi, Y., Carle, M. V., Lehmann, O. J., \& Walter, M. A. (2005). The establishment of a predictive mutational model of the forkhead domain through the analyses of FOXC2 missense mutations identified in patients with hereditary 
lymphedema with distichiasis. Human Molecular Genetics, 14(18), 2619-2627. http://doi.org/10.1093/hmg/ddi295

Brice, G. (2002). Analysis of the phenotypic abnormalities in lymphoedema-distichiasis syndrome in 74 patients with FOXC2 mutations or linkage to 16q24. Journal of Medical Genetics, 39(7), 478-483. http://doi.org/10.1136/jmg.39.7.478

Crisponi L, Uda M, Deiana M, Loi A, Nagaraja R, Chiappe F, Schlessinger D, Cao A, Pilia G. FOXL2 inactivation by a translocation $171 \mathrm{~kb}$ away: analysis of $500 \mathrm{~kb}$ of chromosome 3 for candidate long-range regulatory sequences. Genomics, 83(5), 757-64. http://doi.org/10.1136/jmg.39.7.478

De Gregori, M., Ciccone, R., Magini, P., Pramparo, T., Gimelli, S., Messa, J., et al. (2007). Cryptic deletions are a common finding in "balanced" reciprocal and complex chromosome rearrangements: a study of 59 patients. Journal of Medical Genetics, 44(12), 750-762. http://doi.org/10.1136/jmg.2007.052787

Dekker, J., \& Mirny, L. (2016). The 3D Genome as Moderator of Chromosomal Communication. Cell, 164(6), 1110-1121. http://doi.org/10.1016/j.cell.2016.02.007

Erickson, R. P., Dagenais, S. L., Caulder, M. S., Downs, C. A., Herman, G., Jones, M. C., et al. (2001). Clinical heterogeneity in lymphoedema-distichiasis with FOXC2 truncating mutations. Journal of Medical Genetics, 38(11), 761-766. http://doi.org/10.1136/jmg.38.11.761

Erickson, R. P., Hudgins, L., Stone, J. F., Schmidt, S., Wilke, C., \& Glover, T. W. (1995). A "balanced" Y;16 translocation associated with Turner-like neonatal lymphedema suggests the location of a potential anti-Turner gene on the $\mathrm{Y}$ chromosome. Cytogenetics and Cell Genetics, 71(2), 163-167. http://doi.org/10.1159/000134099

Fang, J., Dagenais, S. L., Erickson, R. P., Arlt, M. F., Glynn, M. W., Gorski, J. L., et al. (2000). Mutations in FOXC2 (MFH-1), a forkhead family transcription factor, are responsible for the hereditary lymphedema-distichiasis syndrome. The American Journal of Human Genetics, 67(6), 1382-1388. http://doi.org/10.1086/316915

Fantes, J. A., Boland, E., Ramsay, J., Donnai, D., Splitt, M., Goodship, J. A., et al. (2008). FISH mapping of de novo apparently balanced chromosome rearrangements identifies characteristics associated with phenotypic abnormality. American Journal of Human Genetics, 82(4), 916-926. http://doi.org/10.1016/j.ajhg.2008.02.007

Flomen, R. H., Vatcheva, R., Gorman, P. A., Baptista, P. R., Groet, J., Barisic, I., et al. (1998). Construction and Analysis of a Sequence-Ready Map in 4q25: Rieger Syndrome Can Be Caused by Haploinsufficiency ofRIEG, but Also by Chromosome Breaks $\approx 90 \mathrm{~kb}$ Upstream of This Gene. Genomics, 47(3), 409-413. http://doi.org/10.1006/geno.1997.5127

Halgren, C., Nielsen, N. M., Nazaryan-Petersen, L., Silahtaroglu, A., Collins, R. L., Lowther, C., et al. (2018). Risks and Recommendations in Prenatally Detected De Novo Balanced Chromosomal Rearrangements from Assessment of Long-Term Outcomes. The American Journal of Human Genetics, 102(6), 1090-1103. http://doi.org/10.1016/j.ajhg.2018.04.005 
Higgins, A. W., Alkuraya, F. S., Bosco, A. F., Brown, K. K., Bruns, G. A. P., Donovan, D. J., et al. (2008). Characterization of Apparently Balanced Chromosomal Rearrangements from the Developmental Genome Anatomy Project. The American Journal of Human Genetics, 82(3), 712-722. http://doi.org/10.1016/j.ajhg.2008.01.011

Howard, M. L., \& Davidson, E. H. (2004). cis-Regulatory control circuits in development. Developmental Biology, 271(1), 109-118. http://doi.org/10.1016/j.ydbio.2004.03.031

Ibn-Salem, J., Köhler, S., Love, M. I., Chung, H.-R., Huang, N., Hurles, M. E., et al. (2014). Deletions of chromosomal regulatory boundaries are associated with congenital disease. Genome Biology, 15(9), 1679. http://doi.org/10.1186/s13059-014-0423-1

Jacobs, P. A., Browne, C., Gregson, N., Joyce, C., \& White, H. (1992). Estimates of the frequency of chromosome abnormalities detectable in unselected newborns using moderate levels of banding. Journal of Medical Genetics, 29(2), 103-108. http://doi.org/10.1136/jmg.29.2.103

Kleinjan, D. A., \& van Heyningen, V. (2005). Long-range control of gene expression: emerging mechanisms and disruption in disease. The American Journal of Human Genetics, 76(1), 8-32. http://doi.org/10.1086/426833

Kumar, S., Carver, C., McCall, S., Brice, G., Ostergaard, P., Mortimer, P., et al. (2007). A family with lymphoedema-distichiasis where identical twins have a discordant phenotype. Clinical Genetics, 71(3), 285-287. http://doi.org/10.1111/j.13990004.2007.00758.x

Lai, C. S., Fisher, S. E., Hurst, J. A., Vargha-Khadem, F., \& Monaco, A. P. (2001). A forkheaddomain gene is mutated in a severe speech and language disorder. Nature, 413(6855), 519-523. http://doi.org/10.1038/35097076

Lai, L. W., Erickson, R. P., Bernas, M., \& Witte, M. H. (2018). From childhood onset lymphedema to fatal fetal hydrops: Possible modifying genes for a FOXC2 mutation. Lymphology, 51(2), 85-88. http://doi.org/1038/35097076

Lupiáñez, D. G., Kraft, K., Heinrich, V., Krawitz, P., Brancati, F., Klopocki, E., et al. (2015). Disruptions of topological chromatin domains cause pathogenic rewiring of geneenhancer interactions. Cell, 161(5), 1012-1025. http://doi.org/10.1016/j.cell.2015.04.004

Nora, E. P., Lajoie, B. R., Schulz, E. G., Giorgetti, L., Okamoto, I., Servant, N., et al. (2012). Spatial partitioning of the regulatory landscape of the $\mathrm{X}$-inactivation centre. Nature ..., 485(7398), 381-385. http://doi.org/10.1038/nature11049

Rao, S. S. P., Huntley, M. H., Durand, N. C., Stamenova, E. K., Bochkov, I. D., Robinson, J. T., et al. (2014). A 3D map of the human genome at kilobase resolution reveals principles of chromatin looping. Cell, 159(7), 1665-1680. http://doi.org/10.1016/j.cell.2014.11.021

Redin, C., Brand, H., Collins, R. L., Kammin, T., Mitchell, E., Hodge, J. C., et al. (2017). The genomic landscape of balanced cytogenetic abnormalities associated with human congenital anomalies. Nature Genetics, 49(1), 36-45. http://doi.org/10.1038/ng.3720 
Roessler, E., Belloni, E., Gaudenz, K., Jay, P., Berta, P., Scherer, S. W., et al. (1996). Mutations in the human Sonic Hedgehog gene cause holoprosencephaly. Nature Genetics, 14(3), 357-360. http://doi.org/10.1038/ng1196-357

Roessler, E., Ward, D. E., Gaudenz, K., Belloni, E., Scherer, S. W., Donnai, D., et al. (1997). Cytogenetic rearrangements involving the loss of the Sonic Hedgehog gene at 7q36 cause holoprosencephaly. Human Genetics, 100(2), 172-181. http://doi.org/10.1007/s004390050486

Sargent, C., Bauer, J., Khalil, M., Filmore, P., Bernas, M., Witte, M., \& Erickson, R. P. (2014). A five generation family with a novel mutation in FOXC2 and lymphedema worsening to hydrops in the youngest generation. American Journal of Medical Genetics Part A, 164(11), 2802-2807. http://doi.org/10.1002/ajmg.a.36736

Schluth-Bolard, C., Delobel, B., Sanlaville, D., Boute, O., Cuisset, J.-M., Sukno, S., et al. (2009). Cryptic genomic imbalances in de novo and inherited apparently balanced chromosomal rearrangements: array CGH study of 47 unrelated cases. European Journal of Medical Genetics, 52(5), 291-296. http://doi.org/10.1016/j.ejmg.2009.05.011

Sholto-Douglas-Vernon, C., Bell, R., Brice, G., Mansour, S., Sarfarazi, M., Child, A. H., et al. (2005). Lymphoedema-distichiasis and FOXC2: unreported mutations, de novo mutation estimate, families without coding mutations. Human Genetics, 117(2-3), 238-242. http://doi.org/10.1007/s00439-005-1275-2

Spielmann, M., Lupiáñez, D. G., \& Mundlos, S. (2018). Structural variation in the 3D genome. Nature Reviews. Genetics, 19(7), 453-467. http://doi.org/10.1038/s41576-018-0007-0

Tavian, D., Missaglia, S., Maltese, P. E., Michelini, S., Fiorentino, A., Ricci, M., et al. (2016). FOXC2 disease-mutations identified in lymphedema-distichiasis patients cause both loss and gain of protein function. Oncotarget, 7(34), 54228-54239. http://doi.org/10.18632/oncotarget.9797

Tavian, D., Missaglia, S., Michelini, S., Maltese, P. E., Manara, E., Mordente, A., \& Bertelli, M. (2020). FOXC2 Disease Mutations Identified in Lymphedema Distichiasis Patients Impair Transcriptional Activity and Cell Proliferation. International Journal of Molecular Sciences, 21(14), 5112. http://doi.org/10.3390/ijms21145112

Thomas, N. S., Morris, J. K., Baptista, J., Ng, B. L., Crolla, J. A., \& Jacobs, P. A. (2010). De novo apparently balanced translocations in man are predominantly paternal in origin and associated with a significant increase in paternal age. Journal of Medical Genetics, 47(2), 112-115. http://doi.org/10.1136/jmg.2009.069716

Trembath, D. G., Semina, E. V., Jones, D. H., Patil, S. R., Qian, Q., Amendt, B. A., et al. (2004). Analysis of two translocation breakpoints and identification of a negative regulatory element in patients with Rieger's syndrome. Birth Defects Research. Part a, Clinical and Molecular Teratology, 70(2), 82-91. http://doi.org/10.1002/bdra.10154

Wallis, D. E., Roessler, E., Hehr, U., Nanni, L., Wiltshire, T., Richieri-Costa, A., et al. (1999). Mutations in the homeodomain of the human SIX3 gene cause holoprosencephaly. Nature Genetics, 22(2), 196-198. http://doi.org/10.1038/9718 
Warburton, D. (1991). De novo balanced chromosome rearrangements and extra marker chromosomes identified at prenatal diagnosis: clinical significance and distribution of breakpoints. The American Journal of Human Genetics, 49(5), 995-1013.

Wild, A., Kalff-Suske, M., Vortkamp, A., Bornholdt, D., König, R., \& Grzeschik, K. H. (1997). Point mutations in human GLI3 cause Greig syndrome. Human Molecular Genetics, 6(11), 1979-1984. http://doi.org/10.1093/hmg/6.11.1979

\section{Acknowledgements}

We would like to thank the family for their cooperation and willingness to be reported.

\section{Author contributions}

Mathew Wallis drafted the manuscript. David Amor and Sharyn Stock-Myer critically revised the manuscript. All authors collected and/or interpreted clinical and/or molecular data of the patients.

\section{Web Resources}

3D Genome Browser: http://promoter.bx.psu.edu/hi-c/

\section{FIGURE LEGENDS}

Figure 1 - Pedigree

Figure 2 - Breakpoint Mapping

a) Using single sperm analysis, the breakpoint of the translocation was mapped to a region approximately $120 \mathrm{~Kb}$ distal to the FOXC2 gene- between GRCh37 Chr16:86,718,757$86,725,305$.

b) Single amplified sperm sample analysed using Human Karyomap-12 bead array and Bluefuse Multi software showing the LogR ratio for the FOXC2 region on chromosome 16. This amplified sperm is unbalanced for the translocation and has a loss of the $16 q$ arm after the breakpoint. Black arrows point to FOXC2 gene and the translocation breakpoint. Decision tracks at the bottom show the location of genes in this region.

Figure 3 - Chromatin interactions at the 16p24.1 locus showing that the translocation breakpoint (green arrow) would likely dissociate FOXC2 from most of its enhancer elements (promoter-enhancer interactions in blue arches)

Approximate location of the 16q24.1 translocation breakpoint is indicated by a green arrow. Chromatin interactions were obtained from 3D Genome Browser (see Web Resources) using the following $\mathrm{Hi}-\mathrm{C}$ parameters: human hg19; human umbilical vein endothelial cell (HUVEC); Lieberman-raw; resolution 25k. The promoter-enhancer interactions were obtained from 3D Genome Browser (see Web Resources) using the following Capture Hi-C parameters: Human, hg19; tissue: endothelial precursors; target: promoter; lab: Fraser; Gene Symbol or 
SNP rsid: FOXC2; extended region in kb (default $\pm 500 \mathrm{~kb}$ ): 850 ; checked to show only interactions for the queried gene or genomic feature.

This article is protected by copyright. All rights reserved. 

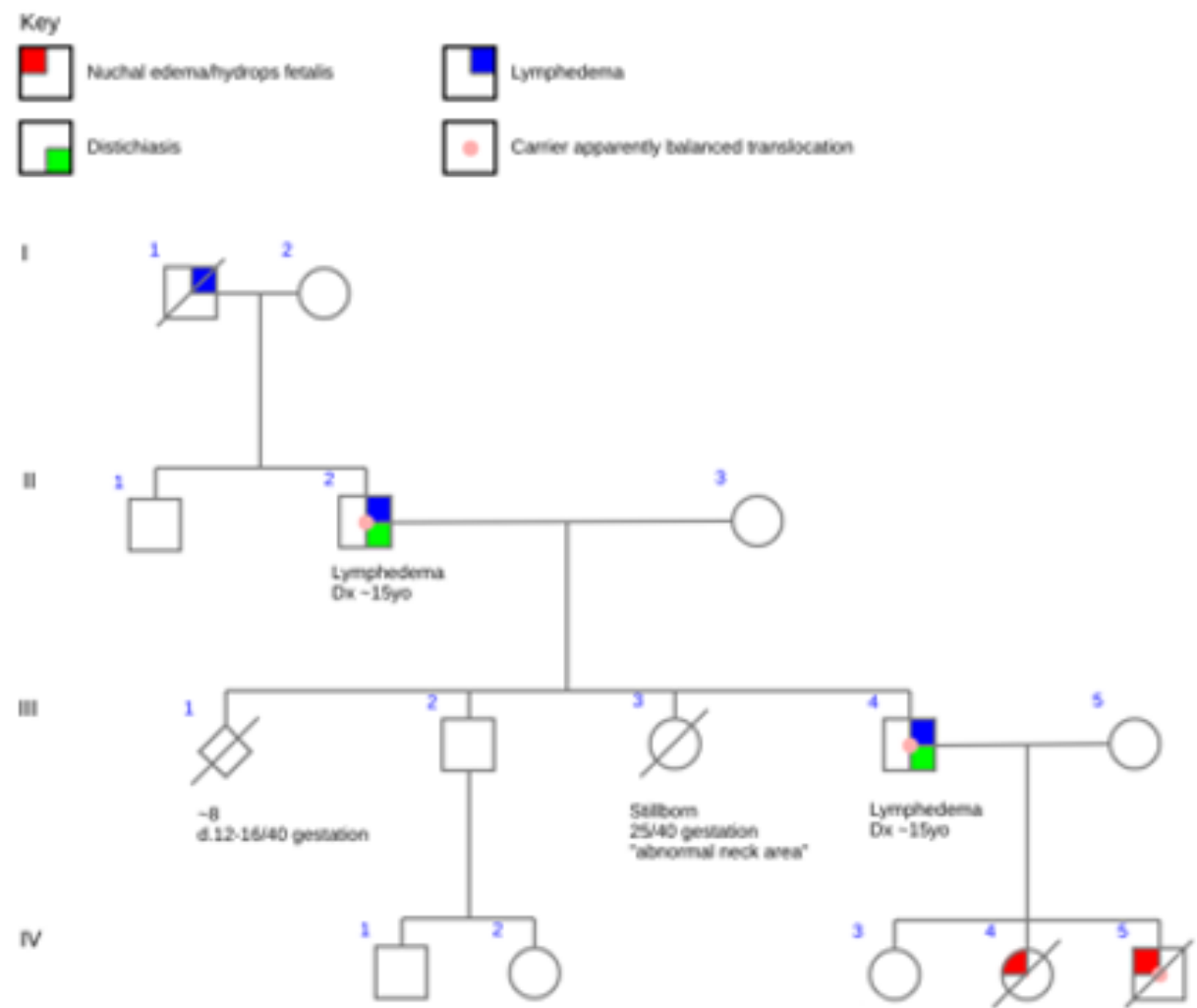

AJMGA_61935_Slide1.tiff

This article is protected by copyright. All rights reserved. 
a)

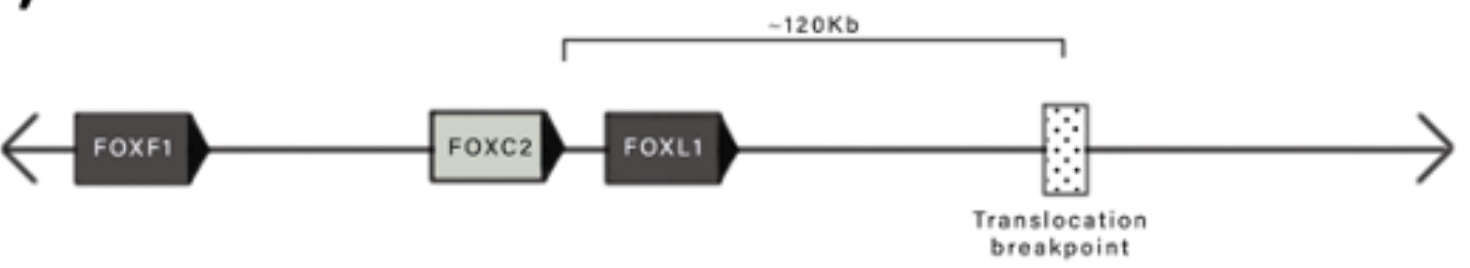

AJMGA_61935_Slide2.tiff

This article is protected by copyright. All rights reserved. 


\section{b)}

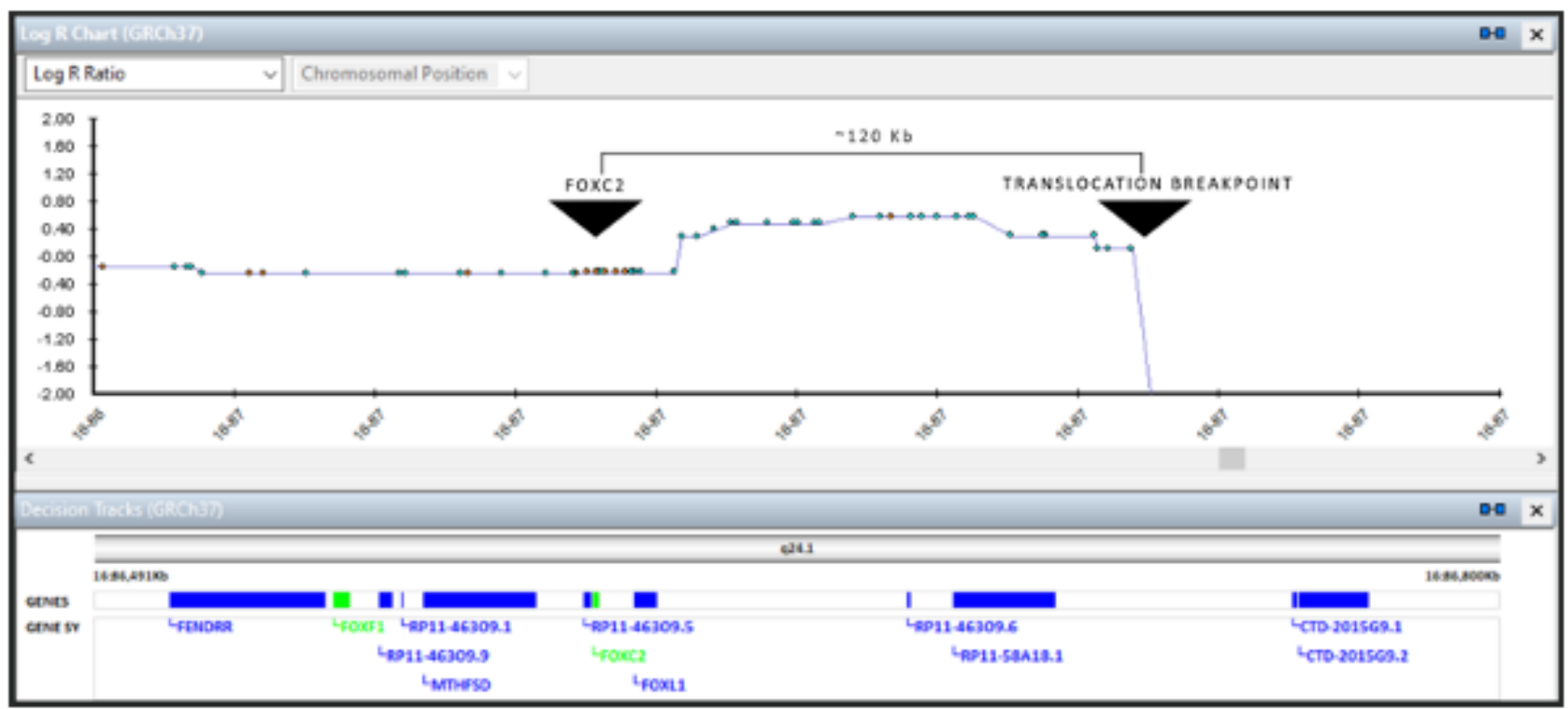

AJMGA_61935_Slide3.tiff

This article is protected by copyright. All rights reserved. 

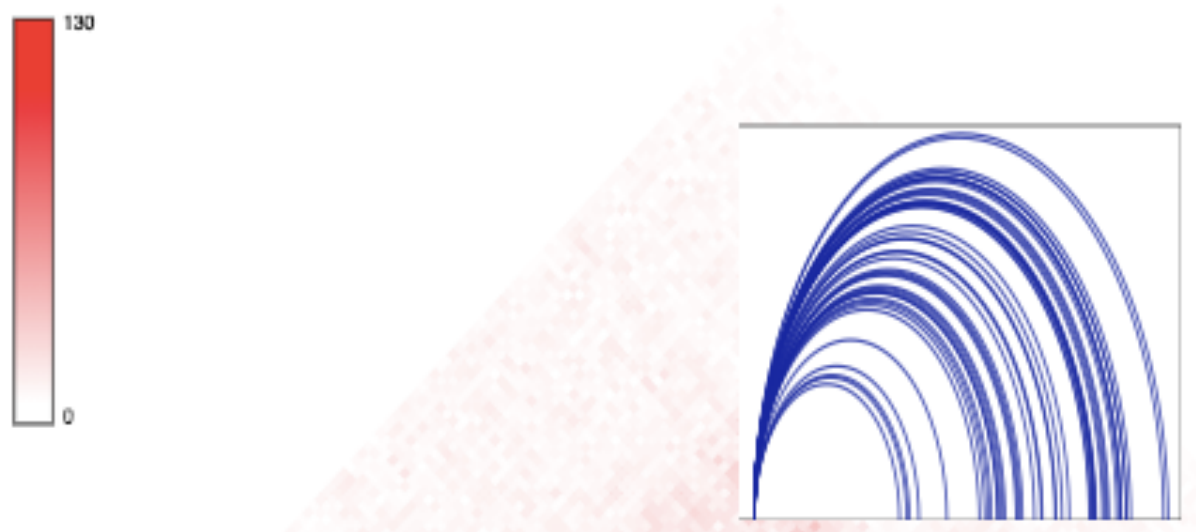

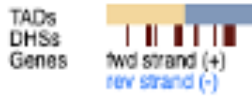

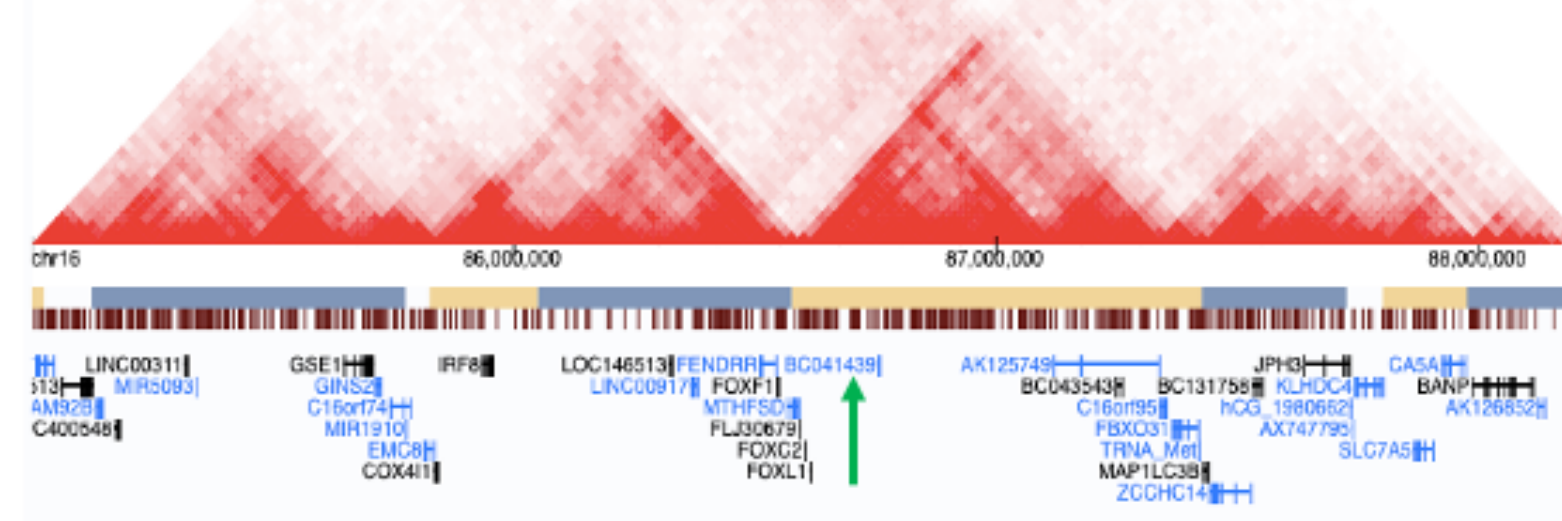

AJMGA_61935_Slide4.tiff

This article is protected by copyright. All rights reserved. 


\section{University Library}

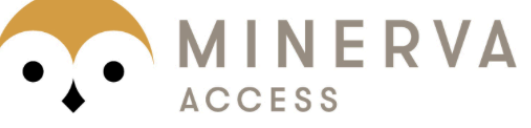

A gateway to Melbourne's research publications

Minerva Access is the Institutional Repository of The University of Melbourne

Author/s:

Wallis, M;Pope-Couston, R;Mansour, J;Amor, DJ;Tang, P;Stock-Myer, S

Title:

Lymphedema distichiasis syndrome may be caused by FOXC2 promoter-enhancer dissociation and disruption of a topological associated domain

Date:

2020-10-27

Citation:

Wallis, M., Pope-Couston, R., Mansour, J., Amor, D. J., Tang, P. \& Stock-Myer, S. (2020). Lymphedema distichiasis syndrome may be caused by FOXC2 promoter-enhancer dissociation and disruption of a topological associated domain. AMERICAN JOURNAL OF MEDICAL GENETICS PART A, 185 (1), pp.150-156. https://doi.org/10.1002/ajmg.a.61935.

Persistent Link:

http://hdl.handle.net/11343/276534 